\title{
Heat of Combustion of Phenyl-Beta-Naphthylamine (N-Phenyl-2-Naphthylamine)
}

\author{
By Donald E. Roberts and Ralph S. Jessup
}

\begin{abstract}
The heat of combustion of purified solid phenyl-beta-naphthylamine, ( $N$-phenyl-2naphthylamine) in forming gaseous carbon dioxide, liquid water, and gaseous nitrogen, has been determined from measurements with a bomb calorimeter. The value obtained $\left(-\triangle H_{c}^{\circ}\right.$ at $\left.25^{\circ} \mathrm{C}\right)$ is $37909.6 \mathrm{int} \mathrm{j} / \mathrm{g}(1987.07 \mathrm{kcal} / \mathrm{mole})$, with an estimated value of $8.3 \mathrm{int} \mathrm{j} / \mathrm{g}(0.43$ $\mathrm{kcal} / \mathrm{mole}$ ) for the standard deviation of the mean, obtained by making allowance for both accidental and systematic errors.
\end{abstract}

\section{Introduction}

Phenyl-beta-naphthylamine ( $N$-phenyl-2-naphthylamine) is one of the most important materials used as stabilizers in the production of synthetic rubber. Stabilizers prevent continued polymerization, cross-linking, or cyclization, which would otherwise cause stiffening during storage of the unvulcanized synthetic rubber. The concentrations used range from 0.10 to 2.0 percent, depending on the type of rubber.

This material is also widely used as an antioxidant in the compounding of natural and synthetic rubbers prior to vulcanization. In this connection it retards oxidative deterioration of the product after vulcanization and improves its resistance to cracking and deterioration by heat. It is sold under the trade names Agerite Powder and Neozone D.

Data on the heat of combustion of phenyl-betanaphthylamine are useful in interpreting the results of heat of combustion measurements on synthetic rubbers, and an accurate value may be desirable for other calculations.

\section{Apparatus and Method}

The measurements of the heat of combustion were made in a bomb calorimeter. The apparatus and procedure are the same as those described previously $[1,2,3,4,5],{ }^{1}$ except in the following

\footnotetext{
${ }^{1}$ Figures in brackets indicate the literature references at the end of this paper.
}

respects: (1) The firing electrode was sealed into the head of the bomb with soda glass instead of the special glass previously used [3], (2) the bomb has two valves, and the carbon dioxide remaining in it after the pressure was reduced to atmospheric following a combustion was flushed out by passing purified oxygen through the bomb, instead of by alternately filling it to a pressure of several atmospheres and releasing the pressure [5].

The calorimetric system was calibrated with Bureau Standard Sample 39f of benzoic acid. The value used for the heat of combustion of this sample under the conditions of the standard bomb process was reported previously [4].

The amount of the combustion reaction in each measurement of heat of combustion was derived from the mass of carbon dioxide formed. The determination of the carbon dioxide, tests for carbon monoxide, and corrections for ignition energy, and for nitric acid formed were the same as described previously [6]. No carbon monoxide was detected in the gaseous products of combustion. A value of $60 \mathrm{kj} / \mathrm{mole}$ of nitric acid was used in correcting for the aqueous nitric acid (about 0.5 molar) formed in the bomb. This correction amounted to about 0.12 percent of the heat of combustion. The nitric acid represented about 7 percent of the total nitrogen present.

Using the procedure described by Washburn [7], modified so as to apply to $30^{\circ} \mathrm{C}$ and to the energy content of the gases at zero pressure instead of 1 atmosphere, the observed heat of combustion in 
each experiment was reduced to the value of $-\Delta U_{c}^{\circ}$, the decrease in intrinsic energy accompanying the combustion reaction:

$$
\begin{aligned}
C_{16} H_{13} N(c)+ & \frac{77}{4} O_{2}(g) \rightarrow 16 C O_{2}(g)+ \\
& \frac{13}{2} H_{2} O(l)+\frac{1}{2} N_{2}(g),
\end{aligned}
$$

with each of the reactants and products in its thermodynamic standard state.

The energy unit used in the original calculation of the results is the international joule. Conversion of the results to terms of the conventional thermochemical calorie was made by use of the relation 1 calorie $=4.1833$ int. j. Conversion to absolute joules may be made by use of the relation 1 int $\mathrm{j}=1.000165$ absolute $\mathrm{j}$.

\section{Material}

The sample used was prepared by F. J. Linnig of this Bureau from a commercial grade material (Agerite Powder, supplied by the R. T. Vanderbilt Co.) by vacuum distillation and two recrystallizations from aviation gasoline. It consisted of nearly white needle crystals with a melting point of approximately $107^{\circ} \mathrm{C}$.

Spectrochemical examination of the unpurified and purified samples of phenyl-beta-napthylamine was made by Martha E. Mayo of this Bureau to determine whether the recrystallized sample had been contaminated with lead from the aviation gasoline. Lead was not detected in either sample. Traces (less than $0.001 \%$ ) of copper and silicon were found in the unpurified material.

\section{Results}

The results of the calibration experiments with benzoic acid are given in table 1 . The results of the measurements of heat of combustion of phenyl-beta-napthylamine are given in table 2 , where $-\Delta U_{B}$ is the observed heat of combustion under the conditions of the bomb process ${ }^{2}$, and $-\Delta U_{c}^{\circ}$ is the decrease in intrinsic energy accompanying the combustion reaction when the reactants and products are all in their thermo-

2 The conditions of the bomb process are specified by the temperature $\left(30^{\circ} \mathrm{C}\right)$ to which the combustion reaction is referred, the mass of water $(1 \mathrm{~g})$ placed in the bomb before each experiment, the internal volume of the bomb $(377 \mathrm{ml})$, and the data given in columns 1 and 2 of table 2 .
TABLE 1. Calibration of calorimeter with benzoic acid

\begin{tabular}{|c|}
\hline $\begin{array}{c}\text { Observed energy equivalent at } 28.5^{\circ} \mathrm{C} \\
\text { int } \boldsymbol{j} /{ }^{\circ} \mathrm{C}\end{array}$ \\
\hline \\
13724.7 \\
13727.6 \\
13723.9 \\
13725.0 \\
13723.1 \\
13724.5 \\
13727.5 \\
13724.2 \\
13730.4 \\
13727.0 \\
13723.2 \\
13729.3 \\
13726.8 \\
-13725.9 \\
Mean ......... \\
Standard deviation \\
of the mean ${ }^{1}, s_{E_{-}}$ \\
\hline
\end{tabular}

1 Standard deviation of the mean, as used here and in table 2 , is defined as $\left[\left(\Sigma d^{2}\right) / n(n-1)\right]^{1 / 2}$, where $d$ is the difference between a single observation and the mean, and $n$ is the number of observations. In the case of the final values of heat of combustion given in table 3 , the values given for the standard deviation include the effects of estimated systematic errors, as well as accidental errors. These values were calculated from the relation

$$
s=Q\left[\left(s_{B} / E\right)^{2}+\left(s_{Q} / Q\right)^{2}+R^{2}+R^{2}\right]^{1 / 2},
$$

where $s_{R}$ is the standard deviation of the mean of the experiments with benzoic acid to determine $E$, the energy equivalent of the calorimetric system; $S_{Q}$ is the standard deviation of the mean of the results of the experiments to determine $Q$, the heat of combustion of the sample; $B$ is an allowance of $5 \times 10^{-5}$ for the standard deviation of the value used for heat of combustion of benzoic acid; and $R$ is an allowance of $2 \times 10^{-4}$ for systematic errors associated with the impurities in the sample and the determination of the amount of the combustion reaction from the mass of carbon dioxide.

\begin{tabular}{|c|c|c|c|c|}
\hline \multirow{2}{*}{$\begin{array}{l}\text { Mass of } \\
\text { sample }\end{array}$} & \multirow{2}{*}{$\begin{array}{l}\text { Initial } \mathrm{O}_{2} \\
\text { pressure } \\
\text { at } 30^{\circ} \mathrm{C}\end{array}$} & \multirow{2}{*}{$\begin{array}{c}\text { Tass of } \\
\mathrm{CO}_{2}\end{array}$} & \multicolumn{2}{|c|}{$\begin{array}{l}\text { Heat of combustion at } \\
30^{\circ} \mathrm{C}\end{array}$} \\
\hline & & & $-\Delta U_{B}$ & $-\Delta U_{c}{ }^{\circ}$ \\
\hline $\begin{array}{c}g \\
0.99480 \\
.96981 \\
.96304 \\
.98986\end{array}$ & $\begin{array}{l}\text { atm } \\
32.4 \\
32.2 \\
32.0 \\
32.7\end{array}$ & $\begin{array}{c}g \\
3.19305 \\
3.11248 \\
3.09107 \\
3.17725\end{array}$ & $\begin{array}{c}\text { int } \mathrm{j} / \mathrm{g} \mathrm{CO} \\
11802.8 \\
11801.5 \\
11799.7 \\
11801.8\end{array}$ & $\begin{array}{c}\text { int } j / g \mathrm{CO}_{2} \\
11795.7 \\
11794.4 \\
11792.7 \\
11794.6\end{array}$ \\
\hline \multicolumn{3}{|l|}{ Mean. - } & & 11794.4 \\
\hline \multicolumn{4}{|c|}{ Standard deviation of the mean, ${ }^{1} Q$} & 0.6 \\
\hline
\end{tabular}

TABLE 2. Bomb-calorimetric measurements on phenyl-betanaphthylamine

1 See footnote 1 , table 1 .

dynamic standard states at $30^{\circ} \mathrm{C}$. In table 3 are given values of heat of combustion per gram and per mole calculated from the mean value given in table 2 , on the assumption that 16 moles $(16 \mathrm{x}$ $44.010 \mathrm{~g}$ ) of carbon dioxide corresponds to 1 mole $(219.272 \mathrm{~g})$ of phenyl-beta-napthylamine $\left(\mathrm{C}_{13} \mathrm{H}_{13} \mathrm{~N}\right.$. 
TABLE 3. Heat of combustion of phenyl-beta-naphthylamine

\begin{tabular}{|c|c|c|c|c|}
\hline & int $\mathrm{j} / \mathrm{g}$ & int $\mathrm{kj} / \mathrm{mole}$ & $\mathrm{cal} / \mathrm{g}$ & $\mathrm{kcal} / \mathrm{mole}$ \\
\hline $\begin{array}{l}-\Delta U_{c}^{\circ}\left(30^{\circ} \mathrm{C}\right) \\
-\Delta H_{c}^{\circ}\left(30^{\circ} \mathrm{C}\right) \\
-\Delta H_{c}^{\circ}\left(25^{\circ} \mathrm{C}\right)\end{array}$ & $\begin{array}{l}37875.8 \\
37907.4 \\
37909.6\end{array}$ & $\begin{array}{l}8305.10 \\
8312.03 \\
8312.51\end{array}$ & $\begin{array}{l}9054.05 \\
9061.60 \\
9062.12\end{array}$ & $\begin{array}{l}1985.30 \\
1986.96 \\
1987.07\end{array}$ \\
\hline Standard deviation of mean', $\mathrm{s}_{\ldots}$ & 8.3 & 1.81 & 1.97 & 0.43 \\
\hline
\end{tabular}

I See footnote 1 , table 1.

The values obtained for the mass of carbon dioxide formed in combustion of phenyl-betanaphthylamine were lower than the stoichiometric amounts calculated from the corresponding masses of sample burned by an average of 0.053 percent, indicating that some impurity was present in the samples. Several measurements of the carbon dioxide formed in combustion of Bureau Standard Sample $39 \mathrm{f}$ of benzoic acid yielded results in agreement with calculated values within less than 0.01 percent on the average. Both the benzoic acid samples and the phenyl-beta-naphthylamine samples were compressed into pellets, which burned completely, leaving no residue.

Two experiments on unpurified Agerite Powder yielded a value for heat of combustion per gram of carbon dioxide formed, which was 0.062 percent lower than that of the purified material. With the unpurified samples, the values obtained for the mass of carbon dioxide formed in combustion were lower than the stoichiometric amounts calculated from the corresponding masses of sample burned by an average of 0.135 percent.

The use of the mass of carbon dioxide formed as a measure of the amount of the combustion reaction is equivalent to assuming that the material burned consists of phenyl-beta-naphthylamine plus inert impurity. If this were true for both the purified and unpurified material, the same value of heat of combustion per gram of carbon dioxide formed would be obtained for both. The fact that different values were obtained for the purified and unpurified materials indicates that the assumption is not true for both materials, and it is not certain that it is true for either. It is possible, therefore, that the results for the purified material reported in tables 2 and 3 may be systematically in error by a few hundredths of a percent due to impurity in the material.

\section{Previous Work}

Lemoult [8] reported the values 9153.39 and $9166.79 \mathrm{cal} / \mathrm{g}$ (mean $9160.1 \mathrm{cal} / \mathrm{g}$ ) as the results of calorimetric measurements of the heat of combustion of phenyl-beta-naphthylamine. His calorimeter was calibrated with naphthalene using $9,664 \mathrm{cal} / \mathrm{g}$ for its heat of combustion. No experimental details were given. His sample melted at $107.5^{\circ} \mathrm{C}$ and contained 6.18 percent of nitrogen (theoretical, by present atomic weights 6.39 percent). In terms of the energy unit used in the present work, the mean of Lemoult's results is calculated to be $-\Delta H_{\mathrm{c}}=1,999 \mathrm{kcal} / \mathrm{mole}$. This value was calculated with the aid of the values reported by Lemoult for naphthalene and phenyl-beta-naphthylamine, a value for the ratio of the heats of combustion of naphthalene and benzoic acid derived from the work of Dickinson [1], and the value [4] for the heat of combustion of benzoic acid used in the present work.

\section{References}

[1] H. C. Dickinson, Bul. BS 11, 189 (1914) S230.

12] E. F. Mueller, Bul. BS 13, 547 (1916) S288.

[3] R. S. Jessup and C. B. Green, J. Research NBS 13, 469 (1934) RP721

[4] R. S. Jessup, J. Research NBS 29, 247 (1942) RP1499.

[5] R. S. Jessup, J. Research NBS 18, 115 (1937) RP966.

[6] D. E. Roberts, W. W. Walton, and R. S. Jessup, J. Research NBS 38, 627 (1947) RP1801.

17] E. W. Washburn, BS J. Research 10, 525 (1933) RP 546.

[8] P. Lemoult, Ann. chim. phys. [8] 10, 395 (1907).

Washington, November 11, 1947. 